\title{
Opening the Pathways to Scholarly Enhancements of Teaching and Learning
}

\begin{abstract}
This short piece, written on behalf of the Publications Advisory Committee (PAC), celebrates Teaching \& Learning Inquirys transition to open access and what that means for the future of the Scholarship of Teaching and Learning. Members of the PAC are Pat Hutchings (US, chair), Sean Brawley (Australia), Mick Healey (UK), Margy MacMillan (Canada), Rebecca Nowacek (US), Tony Ciccone (US), and (ex officio) TL/ co-editors Nancy Chick and Gary Poole.
\end{abstract}

\section{KEYWORDS \\ open access, values}

After three outstanding years of publication, Teaching \& Learning Inquiry (TLI) is now firmly established as a go-to place for scholars of teaching and learning to share and build on one another's work. As the official publication of the International Society for the Scholarship of Teaching and Learning (ISSOTL), and as promised in its mission statement, TLI showcases "quality and variety ... in its explicit methodological pluralism, its call for traditional and new genres, and its international authorship from across career stages." Thus the previous six issues have featured scholarly studies, reviews, reflective case studies, and even poetry from a full range of fields and institutional settings. And as of this (4.1) issue, a new feature has been added to the mix: $T L I$ is now open access.

This move comes after two years of study and deliberation by the ISSOTL Publications Advisory Committee, established by the ISSOTL Board in 2013 and charged with stewardship of the journal's financial health and sustainability and its fit with the needs of the Society and the field. Central to the Committee's thinking in recommending the change-and in the ISSOTL Board's approval of it-have been issues of reach and impact. The new open access format ensures that the work of the Scholarship of Teaching and Learning community is widely and easily available. Many members have, for instance, expressed an interest in being able to post their work on their website and share it through social media with colleagues and students. This will now be possible. Indeed, recent studies of open access articles indicate that they are downloaded and cited more frequently than those that are available only by subscription or behind a paywall.

In this sense, open access is also a reflection of the ISSOTL community's dedication to making significant scholarly work on teaching and learning broadly and freely available to educators and students around the world. The open access model reflects the values of sharing, peer collaboration and review, and inclusivity that shape the work of the Society.

This first open access issue of $T L I$ brings an early taste of some of the features that will now be possible in this online only format. Readers will find things like hyperlinks and color images. But these 
are simply the beginning, as $T L I$ taps into future developments in the digital realm that authors and readers can benefit from. Indeed, as indicated in the Editors' introduction, authors are encouraged to include new features such as digital visual mapping, links to data sets, and video.

In short, the new open access model, and the innovations it will make possible, positions TLI on the cutting edge of both quality and prestige as the journal assumes a leadership role in maintaining rigorous standards and in providing new models of scholarship and its representation.

Finally, in this transition, it is appropriate to recall the important role that Indiana University Press played in TLI's inaugural years. Staff from the Press provided valuable guidance at critical junctures along the way, and the partnership helped to give the new journal visibility and stature. A special debt of gratitude goes to Michael Regoli, Director of Electronic and Journals Publishing at IU Press, who has been a most gracious and professional colleague in helping the Society work out the details of the transition to TLI s new home at the University of Calgary. Gratitude also goes to the Transition Committee that managed the transfer from IU Press to the University of Calgary: co-chairs Dan Bernstein (US) and Margy MacMillan (Canada), Nancy Chick (Canada), Pat Hutchings (US), Beth Marquis (Canada), and Gary Poole (Canada), as well as Tony Ciccone (US) as liaison with the ISSOTL Board.

Change happens slowly in higher education, and innovations must often run parallel with longstanding processes before they truly transform the way we do business. Providing open access to the power of a scholarly approach to teaching and learning will hasten the transformation to new models of scholarship and their representation. ISSOTL and TLI are proud to further that tradition.

Tony Ciccone is Professor Emeritus, University of Wisconsin-Milwaukee, and Past President of ISSOTL.

Pat Hutchings was the Scholar in Residence at Gonzaga University's Center for Teaching and Advising from 2012-2015. She is a former vice president of the Carnegie Foundation for the Advancement of Teaching in the USA.

\footnotetext{
Copyright for the content of articles published in Teaching \& Learning Inquiry resides with the authors, and copyright for the publication layout resides with the journal. These copyright holders have agreed that this article should be available on open access under a Creative Commons Attribution License 4.0 International (https://creativecommons.org/licenses/by/4.0). The only constraint on reproduction and distribution, and the only role for copyright in this domain, should be to give authors control over the integrity of their work and the right to be properly acknowledged and cited, and to cite Teaching \& Learning Inquiry as the original place of publication. Readers are free to share these materials-as long as appropriate credit is given, a link to the license is provided, and any changes are indicated.
} 